
627
Ln $38 t$
Engुin.
no. $3-357$

\section{ENGINEENINE LIBRARY UNIVERSITY OF ILUINOIS \\ I URBANA, ILLINOIS}

CORPS OF ENGINEERS, U. S. ARMY

THE

\title{
UNIFIED SOIL CLASSIFICATION SYSTEM
}

TECHNICAL MEMORANDUM NO. 3-357

PREPARED FOR

OFFICE, CHIEF OF ENGINEERS

BY

WATERWAYS EXPERIMENT STATION

VICKSBURG, MISSISSIPPI

VOLUME 1

MARCH 1953 
CORPS OF ENGINEERS, U. S. ARMY

THE

UNIFIED SOIL CLASSIFICATION SYSTEM

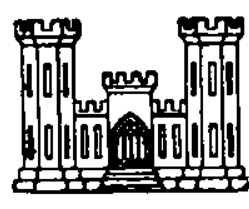

TECHNICAL MEMORANDUM NO. 3-357

\author{
PREPARED FOR \\ OFFICE, CHIEF OF ENGINEERS \\ BY
}

WATERWAYS EXPERIMENT STATION

VICKSBURG, MISSISSIPPI

ARMY-MRC VICKSEURG WISS 

Errata Sheet

"THE UNIFIED SOII CLASSIFICATION SYSTYM

VOLUME 1, MARCH 1953

Line 5 under "Size Range" of tabulation on page 3, now reads:

"No. $4(4.76 \mathrm{~mm})$ "

Please correct to read:

"No. $4(4.76 \mathrm{~mm})$ to No. $200(0.074 \mathrm{~mm})$ "

Table 1

Below is a partial reprint of "Laboratory Classification Criteria, column $7 . "$

Please note that the fourth box (from top) has been changed to read

"Atterberg limits above "A" line with PI greater than $T^{\prime \prime}$

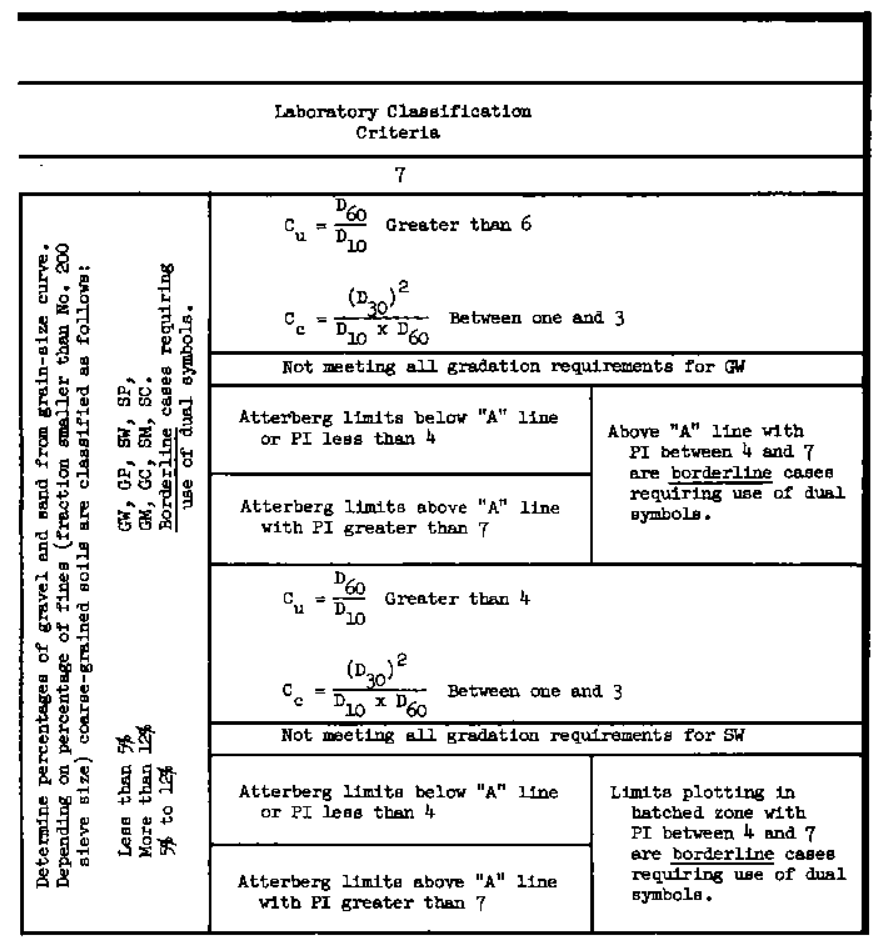





\section{$\underline{\text { Preface }}$}

The purpose of this manual is to describe and explain the use of the "Unified Soil Classification System" in order that identification of soil types will be on a common basis throughout the agencies using this system.

The program of military airfield construction undertaken by the Department of the Army in 1941 revealed at an early stage that existing soil classifications were not entirely applicable to the work in-olved. In 1942 the Corps of Engineers tentatively adopted the "Airfield Classification" of soils which had been developed by Dr. Arthur Casagrande of the Harvard University Graduate School of Engineering. As a result of experience gained since that time, the original classification has been expanded and revised in cooperation with the Bureau of Reclamation so that it applies not only to airfields but also to embankments, foundations, and other engineering features.

Acknowledgment is made to Dr. Arthur Casagrande, Professor of Soil Mechanics and Foundation Engineering, Harvard University, for permission to incorporate in this manual considerable information from the paper "Classification and Identification of Soils" published in Transactions, American Society of Civil Engineers, volume 113, 1948. This manual was prepared under the direction of the Office, Chief of Engineers, by the Soils Division, Waterways Experiment Station. 



\section{Contents}

Page

Preface ...................... . . . i Introduction ..................... I 1 The Classification System ............... 4 Discussion of Coarse-grained Soils . . . . . . . . 6 Discussion of Fine-grained Soils . . . . . . . . . 8 Discussion of Highly Organic Soils . . . . . . . . . 10 Identification of Soil Groups . . . . . . . . . . . . 10 General Identification . . . . . . . . . . . . 11 Laboratory Identification . . . . . . . . . . . 18 Expansion of Classification . . . . . . . . . . . . 27 Descriptive Soil Classification . . . . . . . . . 28 Tables 1-2

Plates 1-9 

UNIFIED SOIL CLASSIFICATION SYSTEM

\section{Introduction}

\section{Need for a classification system}

1. The adoption of the principles of soil mechanics by the engineering profession has inspired numerous attempts to devise a simple classification system that will tell the engineer the properties of a given soil. As a consequence, many classifications have come into existence based on certain properties of soils such as texture, plasticity, strength, and other characteristics. A few classification systems have gained fairly wide acceptance, but it is seldom that any particular system has provided the complete information on a soil that the engineer needs.' Nearly every engineer who practices soil mechanics will add judgment and personal experience as modifiers to whatever soil classification system he uses, so that it may be said that there are as many classification systems as there are engineers using them. Obviously, within a given agency, where designs and plans are reviewed by persons entirely removed from a project, a common basis of soil classification is necessary so that when an engineer classifies a soil as a certain type, this classification will convey to another engineer not familiar with the region the proper characteristics and behavior of the material. Further than this, the classification should reflect those behavior characteristics of the soil that are pertinent to the project under consideration. Basis of the unified soil classification system

2. The unified soil classification system is based on the 
identification of soils according to their textural and plasticity qualities and on their grouping with respect to behavior. Soils seldom exist in nature separately as sand, gravel, or any other single component, but are usually found as mixtures with varying proportions of particles of different sizes; each component part contributes its characteristics to the soil mixture. The unified soil classification system is based on those characteristics of the soil that indicate how it will behave as an engineering construction material. The following properties have been found most useful for this purpose and form the basis of soil identification. They can be determined by simple tests and with experience can be estimated with some accuracy.

a. Percentages of gravel, sand, and fines (fraction passing No. 200 sieve).

b. Shape of the grain-size-distribution curve.

c. Plasticity and compressibility characteristics.

In the unified soil classification system the soil is given a descriptive name and a letter symbol indicating its principal characteristics.

Purpose and scope of manual

3. It is the purpose of this manual to describe the various soil groups in detail and to discuss the methods of identification in order that a uniform classification procedure may be followed by all who use the system. Placement of the soils into their respective groups is accomplished by visual examination and laboratory tests as a means of basic identification. This procedure is described in the main text of this manual. The classification of the soils in these groups according to their engineering behavior for various types of construction, such as 
embankments, foundations, roads, and airfields, is treated separately in appendices hereto which will be issued as the need arises. It is recognized that the unified classification system in its present form may not prove entirely adequate in all cases. However, it is intended that the classification of soils in accordance with this system have some degree of elasticity, and that the system not be followed blindly nor regarded as completely rigid.

Definitions of soil components

4. Before soils can be classified properly in any system, including the one presented in this manual, it is necessary to establish a basic terminology for the various soil components and to define the terms used. In the unified soil classification the names "cobbles," "gravel," "sand," and "fines (silt or clay)" are used to designate the size ranges of soil particles. The gravel and sand ranges are further subdivided into the groups presented below. The limiting boundaries between the various size ranges have been arbitrarily set at certain U. S. Standard sieve sizes in accordance with the following tabulation:

\begin{tabular}{|c|c|}
\hline Component & Size Range \\
\hline Cobbles & Above 3 in. \\
\hline $\begin{array}{l}\text { Gravel } \\
\text { Coarse gravel } \\
\text { Fine gravel }\end{array}$ & $\begin{array}{l}3 \mathrm{in.} \text { to } \mathrm{No} .4(4.76 \mathrm{~mm}) \\
3 \mathrm{in} \text {. to } 3 / 4 \text { in. } \\
3 / 4 \text { in. to No. } 4(4.76 \mathrm{~mm})\end{array}$ \\
\hline $\begin{array}{l}\text { Sand } \\
\text { Coarse sand } \\
\text { Medium sand } \\
\text { Fine sand }\end{array}$ & $\begin{array}{l}\text { No. } 4(4.76 \mathrm{~mm}) \text { to No. } 200(0.074 \mathrm{~mm}) \\
\text { No. } 4(4.76 \mathrm{~mm}) \text { to No. } 10(2.0 \mathrm{~mm}) \\
\text { No. } 10(2.0 \mathrm{~mm}) \text { to No. } 40(0.42 \mathrm{~mm}) \\
\text { No. } 40(0.42 \mathrm{~mm}) \text { to No. } 200(0.074 \mathrm{~mm})\end{array}$ \\
\hline
\end{tabular}

These ranges are shown graphically on the grain-size sheet, plate 1 . In 
the finest soil component (below No. 200 sieve) the terms "silt" and "clay" are used respectively to distinguish materials exhibiting lower plasticity from those with higher plasticity. The minus No. 200 sieve material is "silt" if the liquid limit and plasticity index plot below the "A" line on the plasticity chart (plate 2), and is "clay" if the liquid limit and plasticity index plot above the "A" line on the chart (all Atterberg limits tests based on minus No. 40 sieve fraction of a soil). The foregoing definition holds for inorganic silts and clays and for organic silts, but is not valid for organic clays since these latter soils plot below the "A" line. The names of the basic soil components can be used as nouns or adjectives in the name of a soil, as explained later.

\section{The Classification System}

5. A short discussion of the unified soil classification sheet, table 1 , is presented in order that the succeeding detailed description may be more easily understood. This sheet is designed to apply generally to the identification of soils regardless of the intended engineering uses. The first three columns of the classification sheet show the major divisions of the classification and the group symbols that distinguish the individual soil types. Names of typical and representative soil types found in each group are shown in column 4. The field procedures for identifying soils by general characteristics and from pertinent tests and visual observations are shown in column 5. The desired descriptive information for a complete identification of a soil is presented in column 6 . In column 7 are presented the laboratory 
classification criteria by which the various soil groups are identified and distinguished. Table 2 shows an auxiliary schematic method of classifying soils from the results of laboratory tests. The application and use of this chart are discussed in greater detail under a subsequent heading in this manual.

\section{Soil groups and group symbols}

6. Ma.jor divisions. Soils are primarily divided into coarsegrained soils, fine-grained soils, and highly organic soils. On a textural basis, coarse-grained soils are those that have 50 per cent or less of the constituent material passing the No. 200 sieve, and finegrained soils are those that have more than 50 per cent passing the No. 200 sieve. Highly organic soils are in general readily identified by visual examination. The coarse-grained soils are subdivided into gravel and gravelly soils (symbol G), and sands and sandy soils (symbol S). Fine-grained soils are subdivided on the basis of the liquid limit; symbol $\mathrm{L}$ is used for soils with liquid limits of 50 and less, and symbol $\mathrm{H}$ for soils with liquid limits in excess of 50 (see plate 2). Peat and other highly organic soils are designated by the symbol Pt and are not subdivided.

7. Subdivisions, coarse-grained soils. In general practice there is no clear-cut boundary between gravelly soils and sandy soils, and as far as behavior is concerned the exact point of division is relatively unimportant. For purposes of identification, coarse-grained soils are classed as gravels (G) if the greater percentage of the coarse fraction (retained on No. 200 sieve) is larger than the No. 4 sieve and as sands (S) if the greater portion of the coarse fraction is finer than the No. 4 
sieve. Borderline cases may be classified as belonging to both groups. The gravel (G) and sand (S) groups are each divided into four secondary groups as follows:

a. Well-graded material with little or no fines. Symbol $\mathrm{W}$. Groups GW and SW.

b. Poorly-graded material with little or no fines. Symbol P. Groups GP and SP.

c. Coarse material with nonplastic fines or fines with low plasticity. Symbol M. Groups GM and SM.

d. Coarse material with plastic fines. Symbol C. Groups GC and SC.

8. Subdivisions, fine-grained soils. The fine-grained soils are subdivided into groups based on whether they have a relatively low (I) or high (H) liquid limit. These two groups are further subdivided as follows:

a. Inorganic silts and very fine sandy soils; silty or clayey fine sands; micaceous and diatomaceous soils; elastic silts. Symbol M. Groups ML and MH.

b. Inorganic clays. Symbol C. Groups CL and CH.

c. Organic silts and clays. Symbol 0 . Croups OL and $\mathrm{OH}$.

\section{Discussion of Coarse-grained Soils}

GW and SW groups

9. These groups comprise well-graded gravelly and sandy soils having little or no nonplastic fines (less than 5 per cent passing the No. 200 sieve). The presence of the fines must not noticeably change the strength characteristics of the coarse-grained fraction and must not interfere with its free-draining characteristics. If the material contains less than 5 per cent fines that exhibit plasticity, this 
information should be evaluated and the soil classified as discussed subsequently under "Laboratory Identification." In areas subject to frost action, the material should not contain more than about 3 per cent of soil grains smaller than $0.02 \mathrm{~mm}$ in size. Typical examples of GW and SW soils are shown on plate 3 . GP and SP groups

10. Poorly-graded gravels and sands containing little or no nonplastic fines (less than 5 per cent passing the No. 200 sieve) are classed in the GP and SP groups. The materials may be classed as uniform gravels, uniform sands, or nonuniform mixtures of very coarse material and very fine sand, with intermediate sizes lacking (sometimes called skip-graded, gap-graded, or step-graded). The latter group often results from borrow excavation in which gravel and sand layers are mixed. If the fine fraction exhibits plasticity, this information should be evaluated and the soil classified as discussed subsequently under "Laboratory Identification." Typical examples of various types of GP and SP soils are shown on plate 4 . GM and SM groups

11. In general, the GM and SM groups comprise gravels or sands with fines (more than $12 *$ per cent passing the No. 200 sieve) having low or no plasticity. The plasticity index and liquid limit (based on minus No. 40 sieve fraction) of soils in the group should plot below the "A" line on

* In the preceding two paragraphs soils of the GW, GP, SW, and SP groups were defined as having less than 5 per cent passing the No. 200 sieve. Soils which have between 5 and 12 per cent passing the No. 200 sieve are classed as "borderline" and are discussed in paragraph 33 under that heading. 
the plasticity chart. The gradation of the materials is not considered significant and both well- and poorly-graded materials are included. Some of the sands and gravels in this group will have a binder composed of natural cementing agents, so proportioned that the mixture shows negligible swelling or shrinkage. Thus the dry strength of such materials is provided by a small amount of soil binder or by cementation of calcareous material or iron oxide. The fine fraction of other materials in the GM and SM groups may be composed of silts or rock flour types having little or no plasticity and the mixture will exhibit no dry strength. Typical examples of types of GM and SM soils are shown on plate 5.

$\underline{\mathrm{GC}}$ and SC groups

12. In general, the GC and SC groups comprise gravelly or sandy soils with fines (more than 12 per cent passing the No. 200 sieve) which have either low or high plasticity. The plasticity index and liquid limit of soils (fraction passing the No. 40 sieve) in the group should plot above the "A" line on the plasticity chart. The gradation of the materials is not considered significant and both well- and poorly-graded materials are included. The plasticity of the binder fraction has more influence on the behavior of the soils than does variation in gradation. The fine fraction is generally composed of clays. Typical examples of GC and SC soils are shown on plate 6.

\section{Discussion of Fine-grained Soils}

ML and MH groups

13. In these groups the symbol $M$ has been used to designate 
predominantly silty materials and micaceous or diatomaceous soils. The symbols $\mathrm{L}$ and $\mathrm{H}$ represent low and high liquid limits, respectively, and an arbitrary dividing line between the two is set at a liquid limit of 50. The soils in the ML and MH groups are sandy silts, clayey silts, or inorganic silts with relatively low plasticity. Also included are loess-type soils and rock flours. Micaceous and diatomaceous soils generally fall within the $\mathrm{MH}$ group but may extend into the ML group when their liquid limit is less than 50. The same is true for certain types of kaolin clays and some illite clays having relatively low plasticity. Typical examples of soils in the ML and MH groups are shown on plate 7 .

$\mathrm{CL}$ and $\mathrm{CH}$ groups

14. In these groups the symbol $\mathrm{C}$ stands for clay, with $\mathrm{L}$ and $\mathrm{H}$ denoting low or high liquid limit. The soils are primarily inorganic clays. Low plasticity clays are classified as CL and are usually lean clays, sandy clays, or silty clays. The medium and high plasticity clays are classified as $\mathrm{CH}$. These include the fat clays, gumbo clays, certain volcanic clays, and bentonite. The glacial clays of the northern United States cover a wide band in the CL and CH groups. Typical examples of soils in these groups are shown on plate 8 . $\mathrm{OL}$ and $\mathrm{OH}$ groups

15. The soils in the OL and OH groups are characterized by the presence of organic matter, hence the symbol 0 . Organic silts and clays are classified in these groups. The materials have a plasticity range that corresponds with the ML and $\mathrm{MH}$ groups. Typical examples of OL and $\mathrm{OH}$ soils are presented on plate 9. 
Discussion of Highly Organic Soils

\section{Pt group}

16. The highly organic soils usually are very compressjble and have undesirable construction characteristics. They are not subdivided and are classified into one group with the symbol Pt. Peat, humus, and swamp soils with a highly organic texture are typical soils of the

group. Particles of leaves, grass, branches, or other fibrous vegetable matter are common components of these soils.

\section{Identification of Soil Groups}

17. The unified soil classification is so arranged that most soils may be classified into at least the three primary groups (coarse grained, fine grained, and highly organic) by means of visual examination and simple field tests. Classification into the subdivisions can also be made by visual examination with some degree of success. More positive identification may be made by means of laboratory tests on the materials. However, in many instances a tentative classification determined in the field is of great benefit and may be all the identification that is necessary, depending on the purposes for which the soils in question are to be used. Methods of general identification of soils are discussed in the following paragraphs, and a laboratory testing procedure is presented. It is emphasized that the two methods of identification are never entirely separated. Certain characteristics can only be estimated by visual examination, and in borderline cases it may be necessary to verify the classification by laboratory tests. Conversely, the field 
methods are entirely practical for preliminary laboratory identification and may be used to advantage in grouping soils in such a manner that only a minimum number of laboratory tests need be run.

\section{General Identification}

18. The easiest way of learning field identification of soils is under the guidance of experienced personnel. Without such assistance, field identification may be learned by systematically comparing the numerical test results for typical soils in each group with the "feel" of the material while field identification procedures are being performed. Coarse-grained soils

19. Texture and composition. In field identification of coarsegrained materials a dry sample is spread on a flat surface and examined to determine gradation, grain size and shape, and mineral composition. Considerable experience is required to differentiate, on the basis of a visual examination, between well-graded and poorly-graded soils. The durability of the grains of a coarse-grained soil may require a careful examination, depending on the use to which the soil is to be put. Pebbles and sand grains consisting of sound rock are easily identified. Weathered material is recognized from its discolorations and the relative ease with which the grains can be crushed. Gravels consisting of weathered granitic rocks, quartzite, etc., are not necessarily objectionable for construction purposes. On the other hand, coarsegrained soils containing fragments of shaley rock may be unsuitable because alternate wetting and drying may result in their partial or complete disintegration. This property can be identified by a slaking test. 
The particles are first thoroughly oven- or sun-dried, then submerged in water for at least 24 hours, and finally their strength is tested and compared with the original strength. Some types of shales will completely disintegrate when subjected to such a slaking test.

20. Examination of fine fraction. Reference to the identification sheet (table 1) shows that classification criteria of the various coarsegrained soil groups are based on the amount of material passing the No. 200 sieve and the plasticity characteristics of the binder fraction (passing the No. 40 sieve). Various methods may be used to estimate the percentage of material passing the No. 200 sieve; the choice of method will depend on the skill of the technician, the equipment at hand, and the time available. One method, decantation, consists of mixing the soil with water in a suitable container and pouring of the turbid mixture of water and fine soil; successive decantations will remove practically all of the fines and leave only the sand and gravel sizes in the container. A visual comparison of the residue with the original material will give some idea of the amount of fines present. Another useful method is to put a mixture of soil and water in a test tube, shake it thoroughly, and allow the mixture to settle. The coarse particles will fall to the bottom and successively finer particles will be deposited with increasing time; the sand sizes will fall out of suspension in 20 to 30 seconds. If the assumption is made that the soil weight is proportional to its volume, this method may be used to estimate the amount of fines present. A rough estimate of the amount of fines may be made by spreading the sample out on a level surface and making a visual estimate of the percentage of fine particles present. The presence of fine sand can 
usually be detected by rubbing a sample between the fingers; silt or clay particles feel smooth and stain the fingers, whereas the sand feels gritty and does not leave a stain. The "teeth test" is sometimes used for this purpose, and consists of biting a portion of the sample between the teeth. Sand feels gritty whereas silt and clay do not; clay tends to stick to the teeth while silt does not. If there appears to be more than about 12 per cent of the material passing the No. 200 sieve, the sample should be separated as well as possible by hand, or by decantation and evaporation, removing all of the gravel and coarse sand, and the characteristics of the fine fraction determined. The binder is mixed with water and its dry strength and plasticity characteristics are examined. Criteria for dry strength are shown in column 5 of the classification sheet, table l; evaluation of soils according to dry strength and plasticity criteria is discussed in succeeding paragraphs in connection with fine-grained soils. Identification of active cementing agents other than clay usually is not possible by visual and manual examination, since such agents may require a curing period of days or even weeks. In the absence of such experience the soils should be classified tentatively into their apparent groups, neglecting any possible development of strength because of cementation. Fine-grained soils

21. The principal procedures for field identification of finegrained soils are the test for dilatancy (reaction to shaking), the examination of plasticity characteristics, and the determination of dry strength. In addition, observations of color and odor are of value, particularly for organic soils. Descriptions of the field identification 
procedures are presented in the following paragraphs. The dilatancy, plasticity, and dry strength tests are performed on the fraction of the soil finer than the No. 40 sieve. Separation of particles coarser than the No. 40 sieve is done most expediently in the field by hand. However, separation by hand probably will be most effective for particles coarser than the No. 10 sieve. Some effort should be made to remove the No. 10 to No. 40 fraction but it is believed that any particles in this size range remaining after hand separation would have little effect on the field identification procedures.

22. Dilatancy. The soil is prepared for test by removing particles larger than about the No. 40 sieve size (by hand) and adding enough water, if necessary, to make the soil soft but not sticky. The pat of moist soil. should have a volume of about $1 / 2$ cubic inch. The pat of soil is alternately shaken horizontally in the open palm of one hand, which is struck vigorously against the other hand several times, and then squeezed between the fingers. A fine-grained soil that is nonplastic or exhibits very low plasticity will become livery and show free water on the surface while being shaken. Squeezing will cause the water to disappear from the surface and the sample to stiffen and finally crumble under increasing finger pressure, like a brittle material. If the water content is just right, shaking the broken pieces will cause them to liquefy again and flow together. A distinction may be made between rapid, slow, or no reaction to the shaking test, depending on the speed with which the pat changes its consistency and the water on the surface appears or disappears. Rapid reaction to the shaking test is typical for nonplastic, uniform fine sand, silty sand (SP, SM), and inorganic silts (MI) 
particularly of the rock-flour type, also for diatomaceous earth (MH). The reaction becomes somewhat more sluggish with decreasing uniformity of gradation (and increase in plasticity up to a certain degree). Even a slight content of colloidal clay will impart to the soil some plasticity and slow up materially the reaction to the shaking test. Soils which react in this manner are somewhat plastic inorganic and organic silts (ML, OL), very lean clays (CL), and some kaolin-type clays (ML, MH). Extremely slow or no reaction to the shaking test is characteristic of all typical clays (CL, $\mathrm{CH}$ ) as well as of highly plastic organic clays (OH).

23. Plasticity characteristics. Examination of the plasticity characteristics of fine-grained soils or of the fine fraction of coarsegrained soils is made with a small moist sample of the material. Particles larger than about the No. 40 sieve size are removed (by hand) and a specimen of soil about the size of a $1 / 2-i n$. cube is molded to the consistency of putty. If the soil is too dry, water must be added and if it is sticky, the specimen should be spread out in a thin layer and allowed to lose some moisture by evaporation. The sample is rolled by hand on a smooth surface or between the palms into a thread about $1 / 8$ in. in diameter. The thread is then folded and rerolled repeatedly. During this manipulation the moisture content is gradually reduced and the specimen stiffens, finally loses its plasticity, and crumbles when the plastic limit is reached. After the thread crumbles, the pieces should be lumped together and a slight kneading action continued until the lump crumbles. The higher the position of a soil above the "A" line on the plasticity chart, plate $2(\mathrm{CL}, \mathrm{CH})$, the stiffer are the threads as their water content approaches the plastic limit and the tougher are the lumps as the 
soil is remolded after rolling. Soils slightly above the "A" line (CL, CH) form a medium tough thread (easy to roll) as the plastic limit is approached but when the threads are formed into a lump and kneaded below the plastic limit, the soil crumbles readily. Soils below the "A" line (ML, MH, OL, OH) form a weak thread and, with the exception of the $\mathrm{OH}$ soils, cannot be lumped together into a coherent mass below the plastic limit. Plastic soils containing organic material or much mica (well below the "A" line) form threads that are, very soft and spongy near the plastic limit. The binder fraction of coarse-grained soils may be examined in the same manner as fine-grained soils. In general, the binder fraction of coarse-grained soils with silty fines (GM, SM) will exhibit plasticity characteristics similar to the ML soils, and that of coarsegrained soils with clayey fines (GC, SC) will be similar to the CL soils. 24. Dry strength. The resistance of a piece of dried soil to crushing by finger pressure is an indication of the character of the colloidal fraction of a soil. To initiate the test, particles larger than the No. 40 sieve size are removed from the soil (by hand) and a specimen is molded to the consistency of putty, adding water if necessary. The moist pat of soil is allowed to dry (in oven, sun, or air) and is then crumbled between the fingers. Soils with slight dry strength crumble readily with very little finger pressure. AlI nonplastic ML and MH soils have almost no dry strength. Organic silts and lean organic clays of low plasticity (OL), as well as very fine sandy soils (SM), have slight dry strength. Soils of medium dry strength require considerable finger pressure to powder the sample. Most clays of the CL group and some OH soils exhibit medium dry strength. This is also true of the fine 
fraction of gravelly and sandy soils having a clay binder (GC and SC). Soils with high dry strength can be broken but cannot be powdered by finger pressure. High dry strength is indicative of most $\mathrm{CH}$ clays, as well as some organic clays of the $\mathrm{OH}$ group having very high liquid limits and located near the A-line. In some instances high dry strength in the undisturbed state may be furnished by a cementing material such as calcium carbonate or iron oxide.

25. Color. In field soil surveys color is often helpful in distinguishing between various soil strata, and to an engineer with sufficient preliminary experience with the local soils, color may also be useful for identifying individual soils. The color of the moist soil should be used in identification as soil color may change markedly on drying. To the experienced eye certain dark or drab shades of gray or brown, including almost black colors, are indicative of fine-grained soils containing organic colloidal matter ( $\mathrm{OL}, \mathrm{OH})$. In contrast, brighter colors, including medium and light gray, olive green, brown, red, yellow, and white, are generally associated with inorganic soils. Use of the Munsell soil color charts and plates, prepared for the U. S. Department of Agriculture by the Munsell Color Company, Baltimore, Maryland, is suggested in the event more precise soil color descriptions are desired or to facilitate uniform naming of soil colors.

26. Odor. Organic soils of the OL and $\mathrm{OH}$ groups usually have a distinctive odor which, with experience, can be used as an aid in the identification of such materials. This odor is especially apparent from fresh samples. It gradually diminishes on exposure to air, but can be revived by heating a wet sample. 


\section{Highly organic soils}

27. The field identification of highly organic soils (group Pt) is relatively easy inasmuch as these soils are characterized by undecayed or partially carbonized particles of leaves, sticks, grass, and other vegetable matter which impart to the soil a typical fibrous texture. The color ranges generally from various shades of dull brown to black. A distinct organic odor is also characteristic of the soil. The water content is usually very high. Another aid in identification of these soils may be the location of the soil with respect to topography: low-lying, swampy areas usually contain highly organic soils.

\section{Laboratory Identification}

28. The identification of soils in the laboratory is accomplished by determining the gradation and plasticity characteristics of the materials. The gradation is determined by sieve analysis and a grain-size curve is usually plotted as per cent finer (or passing) by weight against a logarithmic scale of grain size in millimeters. Plate 1 is a typical grain-size chart. Plasticity characteristics are evaluated by means of the liquid and plastic limits tests on the soil fraction finer than the No. 40 sieve. A suggested laboratory method of identification is presented schematically in the chart shown as table 2 and is discussed in the succeeding paragraphs. It should be recognized that although a definite procedure for identification is outlined on the chart, the laboratory technician engaged in classification may be able to use "short cuts" in his work after he becomes thoroughly familiar with the criteria for each soil group. 
Identification of ma,jor soil groups

29. Reference to the identification procedure chart, table 2, shows that the first step in the laboratory identification of a soil is to determine whether it is coarse grained, fine grained, or highly organic. This may be done by visual examination in most cases, using the procedures outlined for field identification. In some borderline cases, as with very fine sands or coarse silts, it may be necessary to screen a representative dry sample over a No. 200 sieve and determine the percentage passing. Fifty per cent or less passing the No. 200 sieve identifies the soil as coarse grained, and more than 50 per cent identifies the soil as fine grained. The percentage limit of 50 has been selected arbitrarily for convenience in identification as it is obvious that a numerical difference of 1 or 2 in this percentage will make no significant change in the behavior of the soil. After the major group in which the soil belongs is established, the identification procedure is continued in accordance with the proper headings in the chart.

Identification of subgroups, coarse-grained soils

30. Gravels (G) or sands (S). A complete sieve analysis is run on coarse-grained soils and the gradation curve is plotted on a grain-size chart. For some soils containing a substantial amount of fines, it may be desirable to supplement the sieve analysis with a hydrometer analysis in order to define the gradation curve below the No. 200 sieve size. Preliminary identification is made by determining the percentage of material in the gravel (above No. 4 sieve) and sand (No. 4 to No. 200 sieve) sizes. If there is a greater percentage of gravel than sand the material is 
classed as gravel (G); if there is a greater percentage of sand than gravel the material is classed as sand (S). Once again the distinction between these groups is purely arbitrary for convenience in following the system. The next identification step is to determine the amount of material passing the No. 200 sieve. Since the subgroups are the same for gravels and sands, they will be discussed jointly in the following paragraphs.

31. GW, SW, GP, and SP groups. These groups comprise nonplastic soils having less than 5 per cent passing the No. 200 sieve and in which the fine fraction does not interfere with the soils' free-draining properties. If the above criteria are met, an examination is made of the shape of the grain-size curve. Materials that are well graded are classified as GW or SW; poorly-graded materials are classified as GP or SP. The grain-size distributions of well-graded materials generally plot as smooth and regular concave curves with no sizes lacking or no excess of material in any size range (plate 3 ); the uniformity coefficient ( 60 per cent grain diameter divided by the 10 per cent grain diameter) of wellgraded gravels is greater than 4, and of well-graded sands is greater than 6 . In addition, the gradation curves should meet the following qualification in order to be classed as well graded.

$$
\begin{gathered}
\frac{\left(D_{30}\right)^{2}}{D_{60} \times D_{10}} \text { between } 1 \text { and } 3 \\
\text { where } D_{30}=\text { grain diameter at } 30 \text { per cent passing } \\
D_{60}=\text { grain diameter at } 60 \text { per cent passing } \\
D_{10}=\text { grain diameter at } 10 \text { per cent passing }
\end{gathered}
$$

The foregoing expression, termed a coefficient of curvature, insures 
that the grading curve will have a concave curvature within relatively narrow limits for a given $D_{60}$ and $D_{10}$ combination. All gradations not meeting the foregoing criteria are classed as poorly graded. Thus, poorly-graded soils (GP, SP) are those having nearly straight line gradations (plate 4, fig. I, curve 3), convex gradations, nearly vertical (uniform) gradations (plate 4, fig. 1, curve 1), and gradation curves with "humps" typical of skip-graded materials (plate 4, fig. 1, curve 2). 32. GM, SM, GC and SC groups. The soils in these groups are composed of those materials having more than a $12^{*}$ per cent fraction passing the No. 200 sieve; they may or may not exhibit plasticity. For identification, the liquid and plastic limits tests are required on the fraction finer than the No. 40 sieve. The tests should be run on representative samples of moist material, and not on air- or oven-dried soils. This precaution is desirable as drying affects the limits values to some extent as will be explained further in the discussion of fine-grained soils. Materials in which the liquid limit and plasticity index plot below the "A" line on the plasticity chart (plate 2) are classed as GM or SM (plate 5). Gravels and sands in which the liquid limit and plasticity index plot above the "A" line on the plasticity chart are classed as GC or SC (plate 6). It is considered that in the identification of materials in these groups the plasticity characteristics overshadow the gradation characteristics; therefore, no distinction is made between well- and poorly-graded materials.

* In the preceding paragraph soils of the GW, GP, SW, and SP groups were defined as having less than a 5 per cent fraction passing the No. 200 sieve. Soils having between 5 and 12 per cent passing the No. 200 sieve are classed as "borderline" and are discussed in paragraph 33. 
33. Borderline soils. Coarse-grained soils containing between 5 and 12 per cent material passing the No. 200 sieve are classed as borderline and carry a dual symbol, e.g., GW-GM. Similarly, coarsegrained soils having less than 5 per cent passing the No. 200 sieve, but which are not free draining, or wherein the fine fraction exhibits plasticity, are also classed as borderline and are given a dual symbol. Additional discussion of borderline classification is presented in paragraphs 38 through 41 .

Identification of subgroups, fine-grained soils

34. Use of plasticity chart. Once the identity of a fine-grained soil has been established, further identification is accomplished principally by the liquid and plastic limits tests in conjunction with the plasticity chart (plate 2). The plasticity chart was developed by Dr. Casagrande as the result of considerable experience with the behavior of soils in many different regions. It is a plot of liquid limit versus plasticity index on which is imposed a diagonal line called the "A" line and a vertical line at a liquid limit of 50. The "A" Iine is defined by the equation $P I=0.73$ (LL-20) except in the lower portion below a liquid limit of about 29 , where it becomes a horizontal zone extending from $P I=4$ to $P I=7$. The " $\mathrm{A}$ " line represents an important empirical boundary between typical inorganic clays (CL and $\mathrm{CH}$ ), which are generally located above the line, and plastic soils containing organic colloids (OL and $\mathrm{OH}$ ) or inorganic silty soils (ML and $\mathrm{MH}$ ). The vertical line at liquid limit of 50 separates silts and clays of low liquid limit (L) from those of high liquid limit (H). In the lower 
portion of the chart below a liquid limit of about 29 and in the range of PI from 4 to 7 there is considerable overlapping of soil properties of the clayey and silty soil types. Hence, the "A" line in this region has been shown as a zone, and soils falling within it should be classed as borderline as discussed subsequently. The various soil groups are shown in their respective positions on the plasticity chart. Experience has shown that compressibility is approximately proportional to liquid limit and that soils having the same liquid limit possess approximately equal compressibility, assuming that other factors are essentially the same. On comparing the physical characteristics of soils having the same liquid limit, one finds that with increasing plasticity index, the cohesive characteristics increase and the permeability decreases. From plots of the results of limits tests on a number of samples from the same fine-grained deposit it is found that for most soils these points lie on a straight line or in a narrow band approximately parallel to the "A" line. With this background information in mind, the identification of the various groups of fine-grained soils is discussed in the following paragraphs.

35. ML, CL, and OL groups. A soil having a liquid limit of less than 50 falls into the low liquid limit (L) group. A plot of the liquid limit and plasticity index on the plasticity chart will show whether it falls above or below the "A" line. Soils plotting above the "A" line are classed as CL and are usually typical inorganic clays (plate 8, fig. 1). Soils plotting below the "A" line are inorganic silts or very fine sandy silts, ML (plate 7, fig. 1), or organic silts or organic siltclays of low plasticity, oL (plate 9, fig. 1). Since two groups fall 
below the "A" line, further identification is necessary. The distinguishing factor between the ML and OL groups is the absence or presence of organic matter. This is usually identified by color and odor as explained in the preceding paragraphs under field identification. However, in doubtful cases a comparison may be made between the liquid and plastic limits on a moist sample and one that has been oven-dried. An organic soil will show a radical drop in plasticity after oven-drying or air-drying. An inorganic soil will generally show a change in the limits values of only 1 or 2 per cent which may be either an increase or a decrease. For the foregoing reasons the classification should be based on the plot of limits values determined before drying. Soils containing organic matter generally have lower specific gravities and may have decidedly higher water contents than inorganic soils; therefore, these properties may be of assistance in identifying organic soils. In special cases, the determination of organic content may be made by chemical methods, but the procedures just described are usually sufficient. 36. $\mathrm{MH}, \mathrm{CH}$, and $\mathrm{OH}$ groups. Soils with a liquid limit greater than 50 are classed in group $H$. To identify such soils, the liquid limit and plasticity index values are plotted on the plasticity chart. If the points fall above the "A" line, the soil classifies as $\mathrm{CH}$; if it falls below the "A" line, a determination is made as to whether or not organic material is present, as described in the preceding paragraph. Inorganic materials are classed as $\mathrm{MH}$ and organic materials are classed as $\mathrm{OH}$. Identification of highly organic soils

37. Little more can be said as to the laboratory identification of highly organic soils (Pt) than has been stated previously under field 
identification. These soils are usually identified readily on the basis of color, texture, and odor. Moisture determinations usually show a natural water content of several hundred per cent, which is far in excess of that found for most soils. Specific gravities of the solids in these soils may be quite low. Some peaty soils can be remolded and tested for liquid and plastic limits. Such materials usually have a liquid limit of several hundred per cent and fall well below the "A" line on the plasticity chart. Borderline classifications

38. It is inevitable in the use of the classification system that soils will be encountered that fall close to the boundaries established between the various groups. In addition, boundary zones for the amount of material passing the No. 200 sieve and for the lower part of the plasticity chart have been incorporated as a part of the system, as discussed in subsequent paragraphs. The accepted rule to follow in classifying borderline soils is to use a double symbol; for example, GW-GM. It is possible, in rare instances, for a soil to fall into more than one borderline zone and, if appropriate symbols were used for each possible classification, the result would be a multiple designation consisting of three or more symbols. This approach is unnecessarily complicated and it is considered best to use only a double symbol in these cases, selecting the two that are believed most representative of the probable behavior of the soil. In cases of doubt the symbols representing the poorer of the possible groupings should be used.

39. Coarse-grained soils. It will be recalled that in previous discussions (paragraph 31) the coarse-grained soils were classified in 
the GW, GP, SW, and SP groups if they contained less than 5 per cent of material passing the No. 200 sieve. Similarly, soils were classified in the GM, GC, SM, and SC groups if they had more than 12 per cent passing the No. 200 sieve (paragraph 32). The range between 5 and 12 per cent passing the No. 200 sieve is designated as borderline and soils falling within it are assigned a double symbol depending on both the gradation characteristics of the coarse fraction and the plasticity characteristics of the minus No. 40 sieve fraction. For example, a wellgraded sandy soil with 8 per cent passing the No. 200 sieve and with $\mathrm{LI}=28$ and $\mathrm{PI}=9$ would be designated as SW-SC. Another type of borderline classification occurs for those soils containing appreciable amounts of fines, groups GM, GC, SM, and SC, and whose Atterberg limits values plot in the lower portion of the plasticity chart. The method of classifying these soils is the same as for fine-grained soils plotting in the same region, as presented in the following paragraph.

40. Fine-grained soils. Mention has been made that the lower portion of the "A" line on the plasticity chart (plate 2) turns in a horizontal direction below a liquid limit of about 29 and becomes a zone ranging between plasticity index values of 4 and 7 . Several soil types exhibiting low plasticity plot in this general region on the plasticity chart and no definite boundary between silty and clayey soils exists. Thus, if a fine-grained soil, groups CL and ML, or the minus No. 40 sieve fraction of a coarse-grained soil, groups GM, GC, SM, and SC, plots within the shaded zone on the plasticity chart, a double symbol (ML-CL, etc.) will be used.

41. "Silty" and "clayey." It will be noted on the classification 
sheet, table 1, that the adjectives "silty" and "clayey" may be used as part of the descriptive name for silt or clay soils. Since the definitions of these terms are now somewhat different from those used by many soils engineers, it is considered advisable to discuss their connotation as used in this system. In the unified soil classification the terms "silt" and "clay" are used to describe those soils with Atterberg limits plotting respectively below and above the "A" line on the plasticity chart. As a logical extension of this concept, the terms "silty" and "clayey" may be used as adjectives in the soil names when the limits values plot close to the "A" line. For example, a clay soil with $L L=40$ and $\mathrm{PI}=16$ may be called a silty clay. In general, it is considered that the adjective "silty" should not be applied to clay soils having a liquid limit in excess of about 60 .

\section{Expansion of Classification}

42. It may be necessary, in some cases, to expand the unified classification system by subdivision of existing groups in order to classify soils for a particular use. The indiscriminate use of subdivisions is discouraged and careful study should be given any soil group before such a step is adopted. In all cases subdivisions should be designated preferably by a suffix to an existing group symbol. The suffix should be selected carefully so that there will be no confusion with existing letters that already have meanings in the classification system. In each case where an existing group is subdivided, the basis and criteria for the subdivision should be explained in order that anyone unfamilar with it may understand the subdivision properly. 


\section{Descriptive Soil Classification}

43. At many stages in the soils investigation of a project -from the preliminary boring log to the final report -- the engineer finds it convenient to give the soils he is working with a "name" rather than an "impersonal" classification symbol such as GC. This results primarily from the fact that he is accustomed to talking in terms of gravels, sands, silts, and clays, and finds it only logical to use these same names in presenting the data. The soil names have been associated with certain grain sizes in the textural classification as shown on the grain-size chart, plate 1 . Such a division is generally feasible for the coarse-grained soils; however, the use of such terms as silt and clay may be entirely misleading on a textural basis. For this reason the terms "silt" and "clay" have been defined on a plasticity basis as discussed previously. Within a given region of the country, use of a name classification based on texture is often feasible since the general behavior of similar soils is consistent over the area. However, in another area the same classification may be entirely inadequate. The descriptive classification, if used intelligently, has a rightful place in soil mechanics, but its use should be carefully evaluated by all concerned.

Description from classification sheet

44. Column 4 of the classification sheet, table 1, lists typical names given the soil types usually found within the various classification groups. By following either the field or laboratory investigation procedure and determining the proper classification group in which the soil 
belongs, it is usually an easy matter to select an appropriate name from the classification sheet. Some soils may be readily identified and properly named by only visual inspection. A word of caution is considered appropriate on the use of the classification system for certain soils such as marls, caliches, coral, shale, etc., where the grain size can vary widely depending on the amount of mechanical breakdown of soil particles. For these soils the group symbol and textural name have little significance and the locally used name may be important. Other descriptive terms

45. Records of field explorations in the form of boring logs can be of great benefit to the engineer if they include adequate information. In addition to the group symbol and the name of the soil, the general characteristics of the soils as to plasticity, strength, moisture, etc., provide information essential to a proper analysis of a particular problem. Locally accepted soil names should also be used to clarify the data to local bidders, and to protect the Government against later legal claims. For coarse-grained soils, the size of particles, mineralogical composition, shape of grains, and character of the binder are relevant features. For fine-grained soils, strength, moisture, and plasticity characteristics are important. When describing undisturbed soils such characteristics as stratification, structure, consistency in the undisturbed and remolded states, cementation, drainage, etc., are pertinent to the descriptive classification. Pertinent items to be used in describing soils are shown in column 6 of table 1. In order to achieve uniformity in estimating consistency of soils, it is recommended that the Terzaghi classification based on unconfined compressive strength be 
used as a tentative standard. This classification is given below:

Unconfined Compressive Strength Tons/Sq Ft

Consistency
Very soft
Soft
Medium
Stiff
Very stiff
Hard

Several examples of descriptive classifications are shown below:

a. Uniform, fine, clean sand with rounded grains (SP).

b. Well-graded gravelly silty sand; angular chert gravel, 1/2-in. maximum size; silty binder with low plasticity, well-compacted and moist (SM).

c. Light brown, fine, sandy silt; very low plasticity; saturated and soft in the undisturbed state (ML).

d. Dark gray, fat clay; stiff in the undisturbed state; soft and sticky when remolded $(\mathrm{CH})$. 
TABLES 

Table

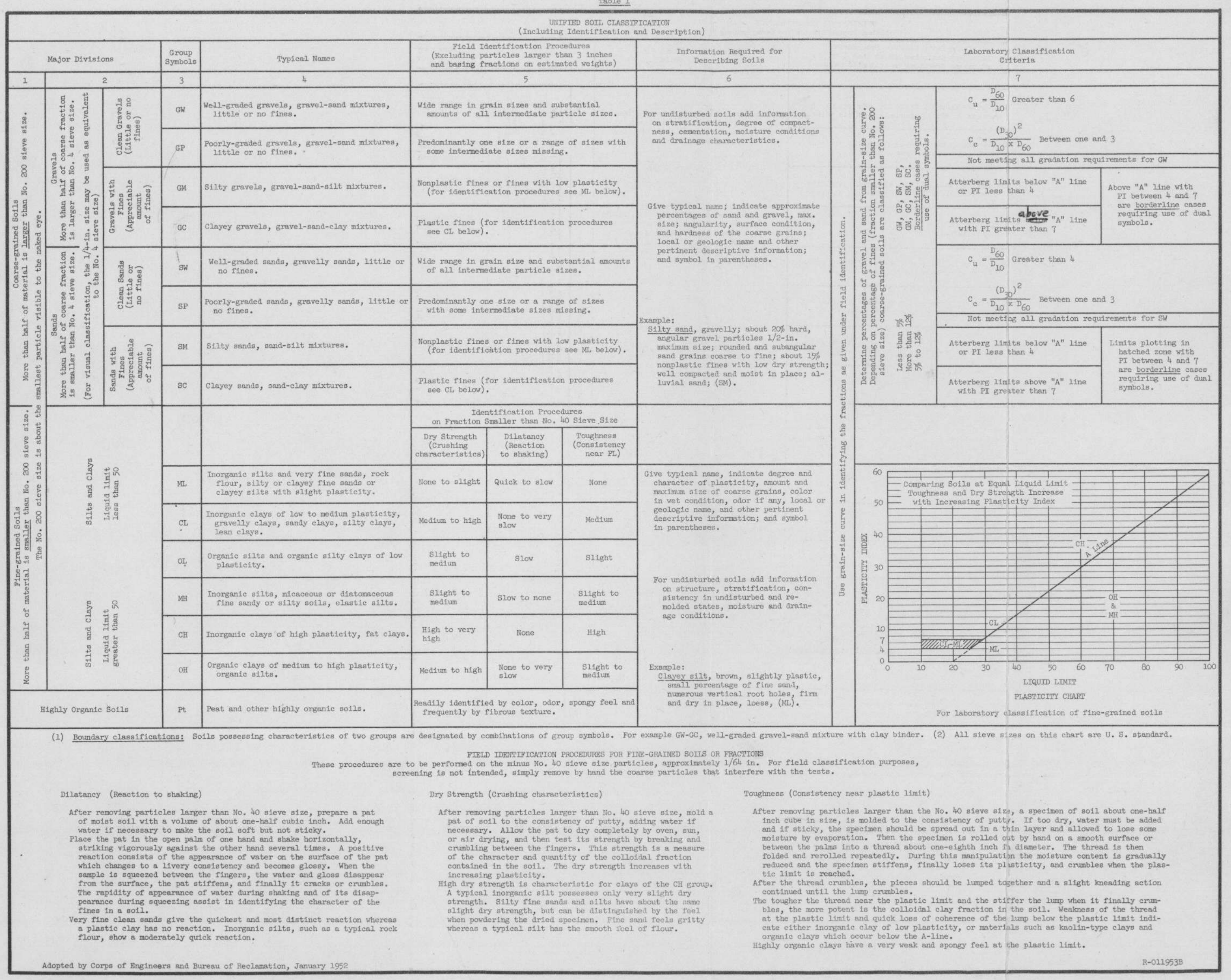



Table 2

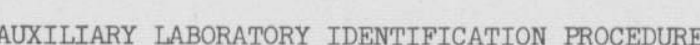

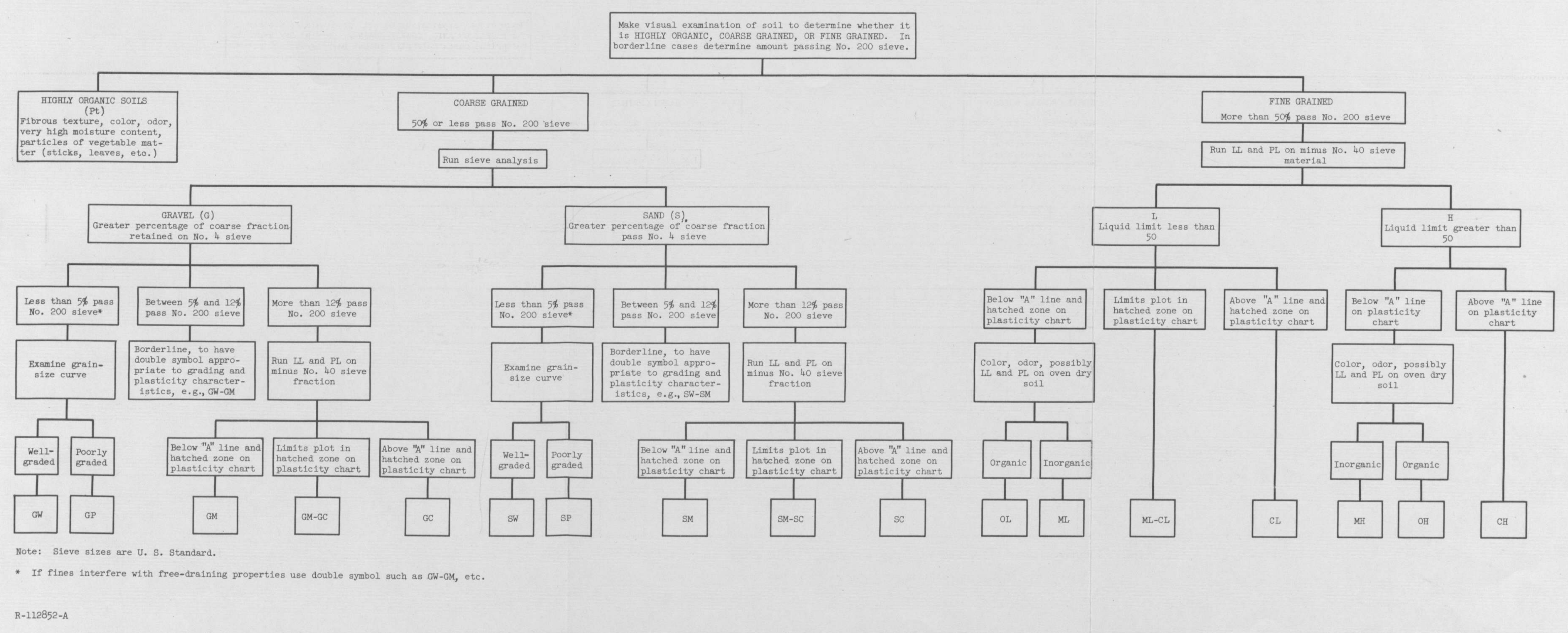



PLATES 








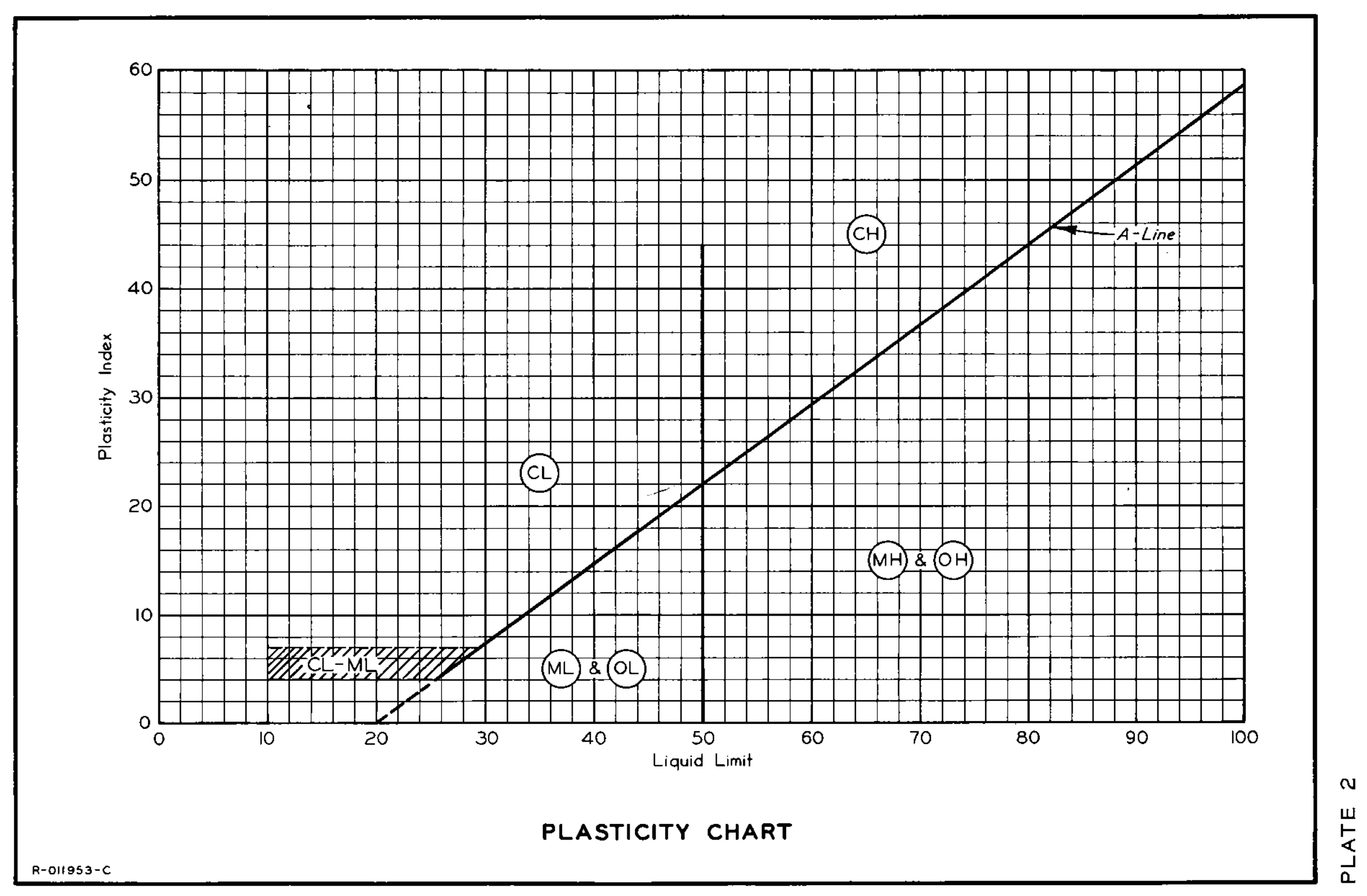




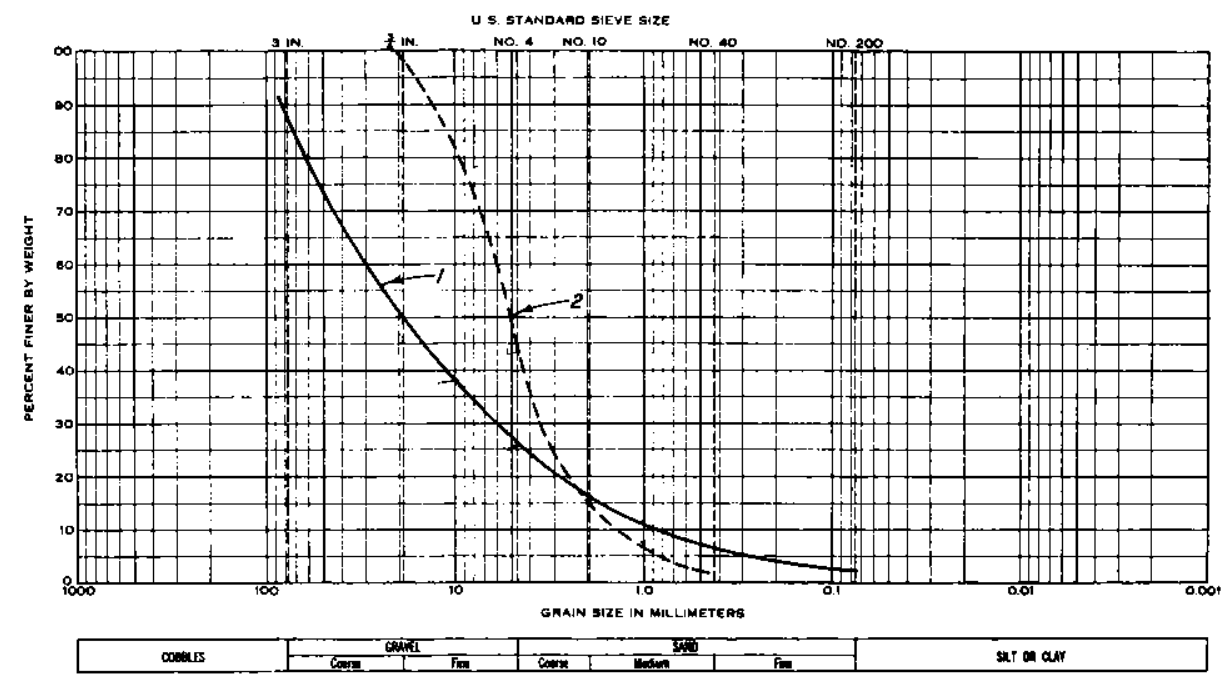

CURVE 1: Pit run gravel; nonplast1c; well-graded; small percentage of f1nes.

CURVE 2: Sandy Eravel; nonplastic; no f1nes. Curve is about the steepest one that vill meet the criteris for

GW GROUP

FIG. I

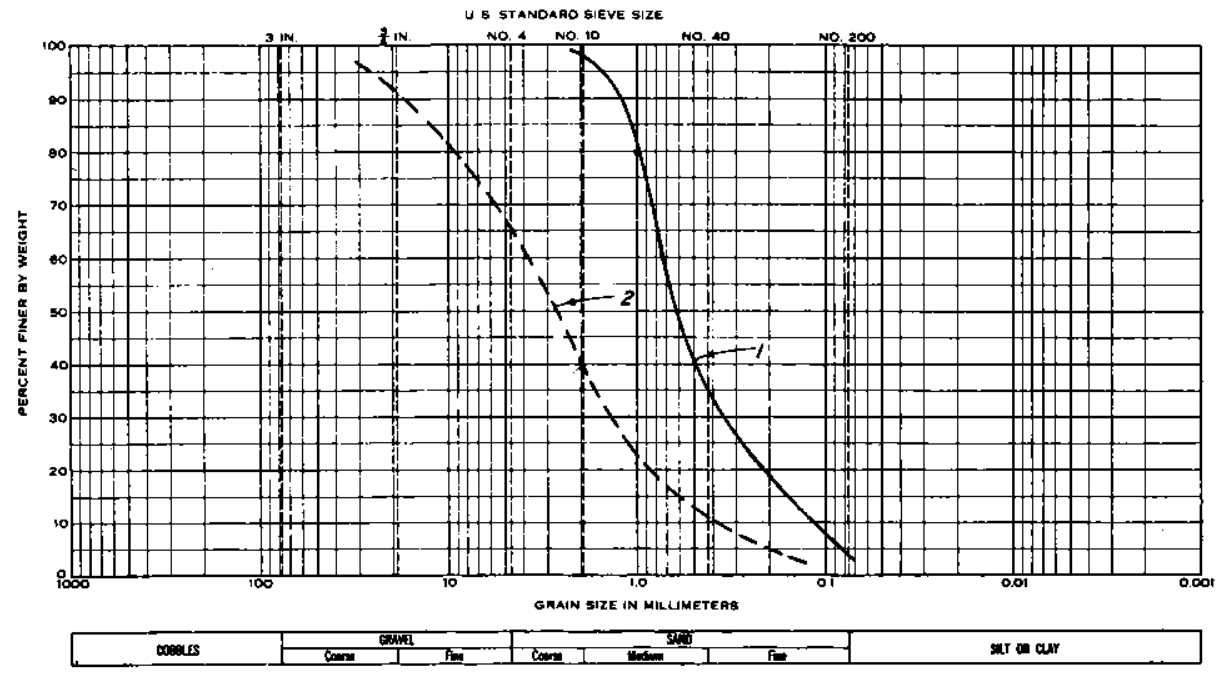

CURVE 1: Med1um to fine sand; nonplastic; well-graded. Curve 1s about the steepest one that will meet the criCURVE 2:- Gravelly sand; nonplast1c; well-graded.

\section{SW GROUP \\ FIG. 2}

TYPICAL EXAMPLES GW AND SW SOILS

$062052-A$ 




GMAIN SIZE IN MILLIMETERS

CURVE 1: Uniform cosrse orave 1; nonplast1c. Very untform gradation.

CURVE 2: Gravel-sand mixture; nonplastic. Gravel 1s almost all of one size (3/4- to 1-1a.), no fine gravel

CURve 3: present. Poorly graded.

GP GROUP

FIC. I



CURVE 1: Uniform fine send; nonplastic.



CURVE 3: Coarse to

SP GROUP

FIG. 2

TYPICAL EXAMPLES GP AND SP SOILS 



CURVE i: Crushed l1mestone; LL-16, PI-E. Well-graded. Made excellent base course material.

CURVE 2: Gravel-sand-silt m1xture; LI-32, PI-6. Poorly graded.

\section{GM GROUP}

FIG. I

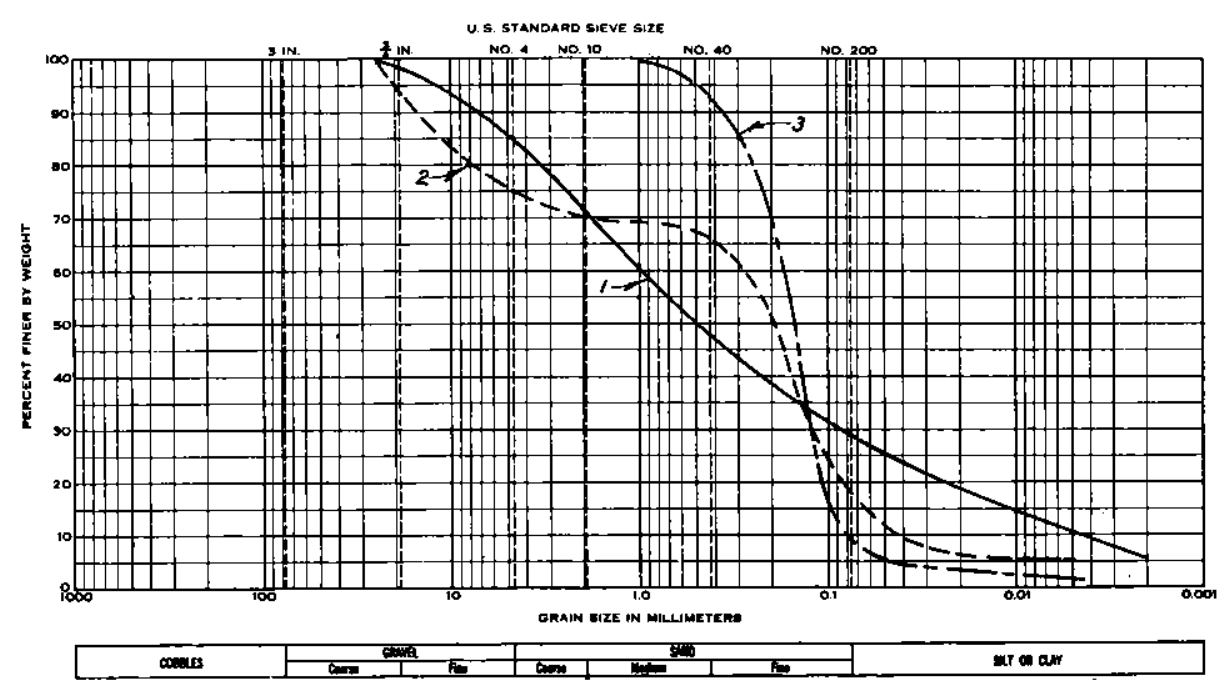

CURVE 1: Stlty gravelly sand; nonplantic. M1caceous ollt stabllized with aendy chert gravel. CURVE 2: Mixture of gravel-sand and flne silty sand; nopplastic. Pooriy oraded mixture; note absence of cosrae

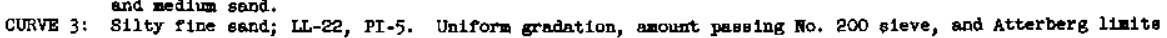
clasalfy sot1 \& borderj.1ne in SP-SM-SC groupg. Cinisify as SP-SM.

SM GROUP

FIG. 2

TYPICAL EXAMPLES

GM AND SM SOILS 




CURVE 1: Clay-gravel (chert); LE-40, PI-19. Falrly low percentage of plastic fines.

CURVE 2: Natural mixture of gravel and clay; LL-46, PI-20. Very poorly graded; almost no sand eizes present.

GC GROUP

FIG. I

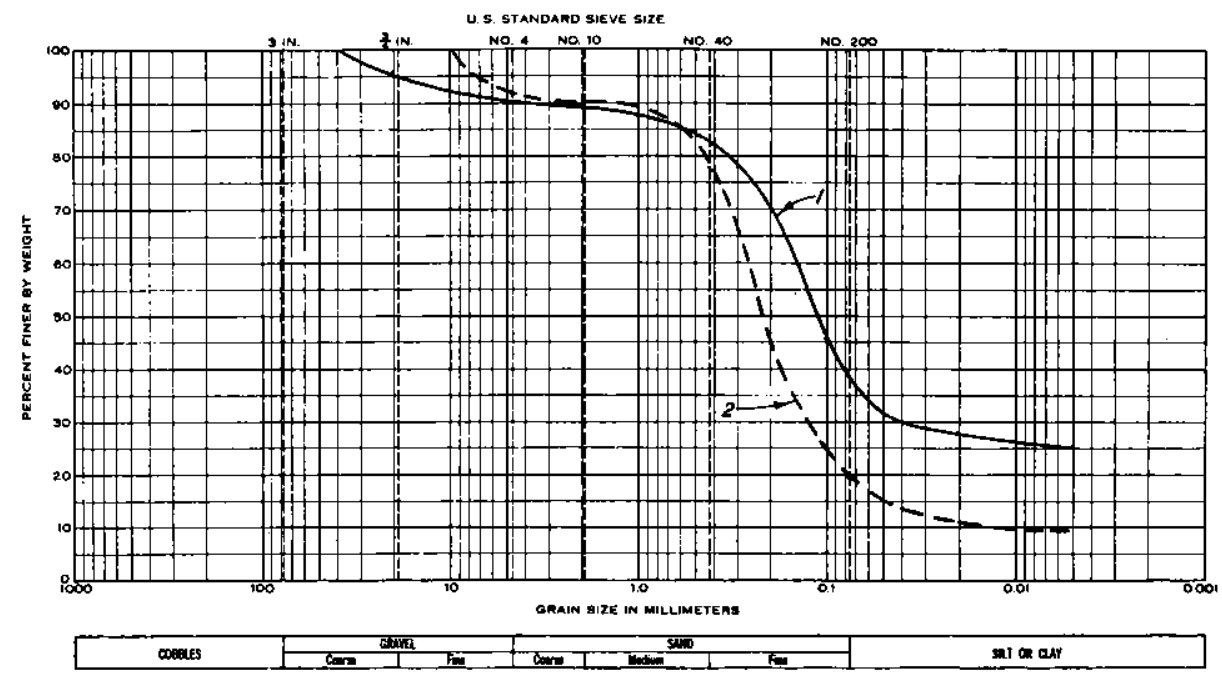

CURVE 1: Clayey sand; LL-23, PI-10. Poorly graded mixture of sand-clay and f1ne ailty sand.

CURVE 2: Limerock and sand wixture; LL-23, PI-8. Poorly graded.

SC GROUP

FIG. 2

TYPICAL EXAMPLES

GC AND SC SOILS

$062652-0$

PLATE 6 


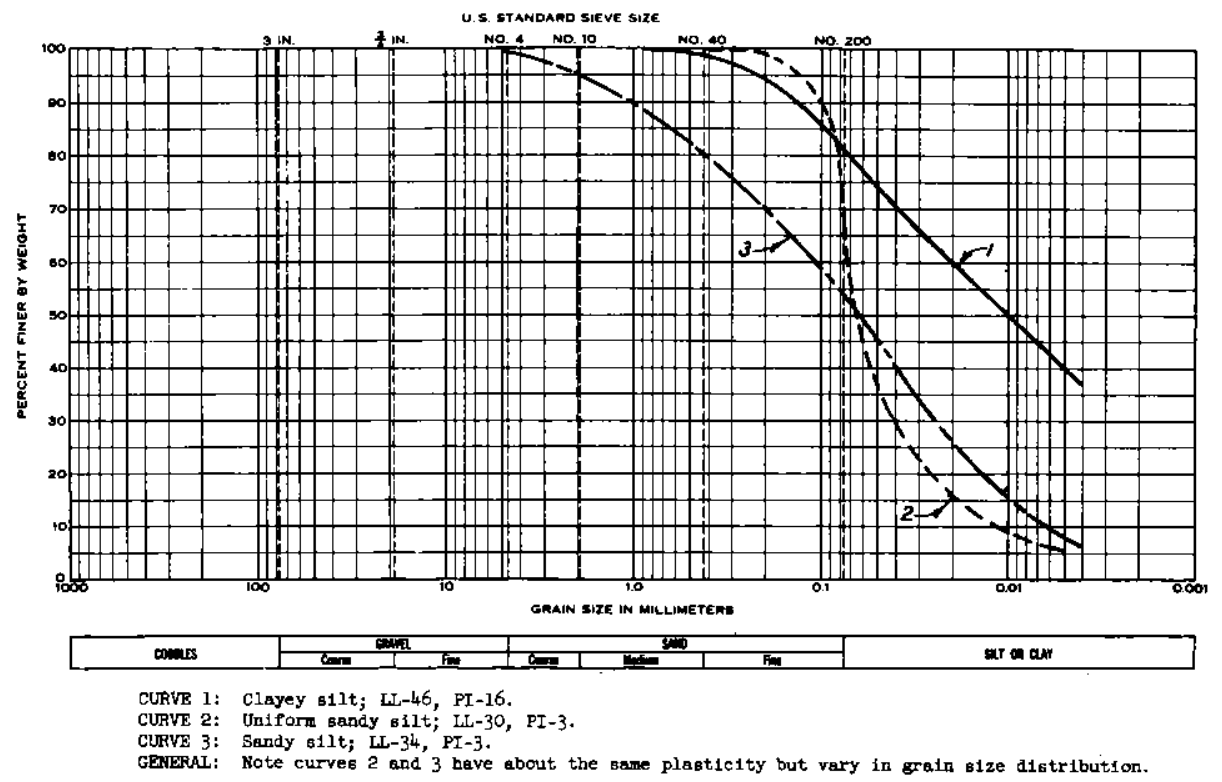

ML GROUP

FIG. 1

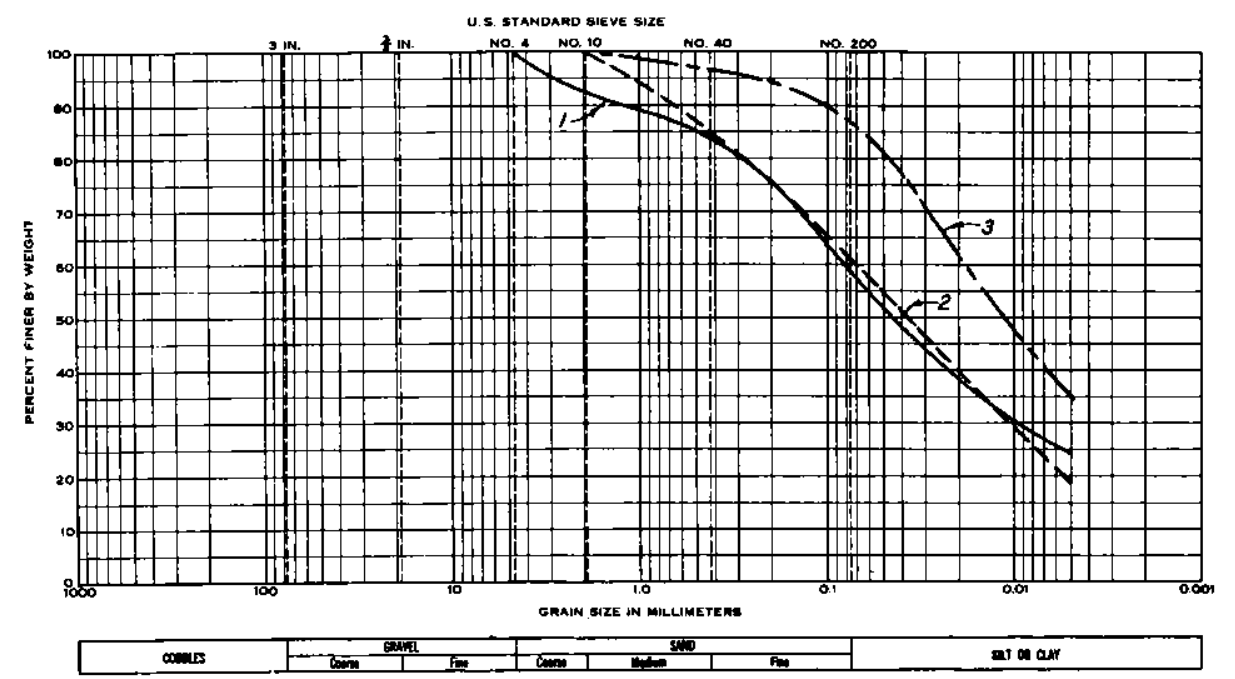

CURVE 1: K1caceous sandy B11t; LL-55, PI-6.

CURVE 2: Sandy 911t; LL-67, PI-27.

GENERAL: Note curves 1 and 2 have approximately the same grain olze but are videly different in plast1city. MH GROUP

FIG. 2 


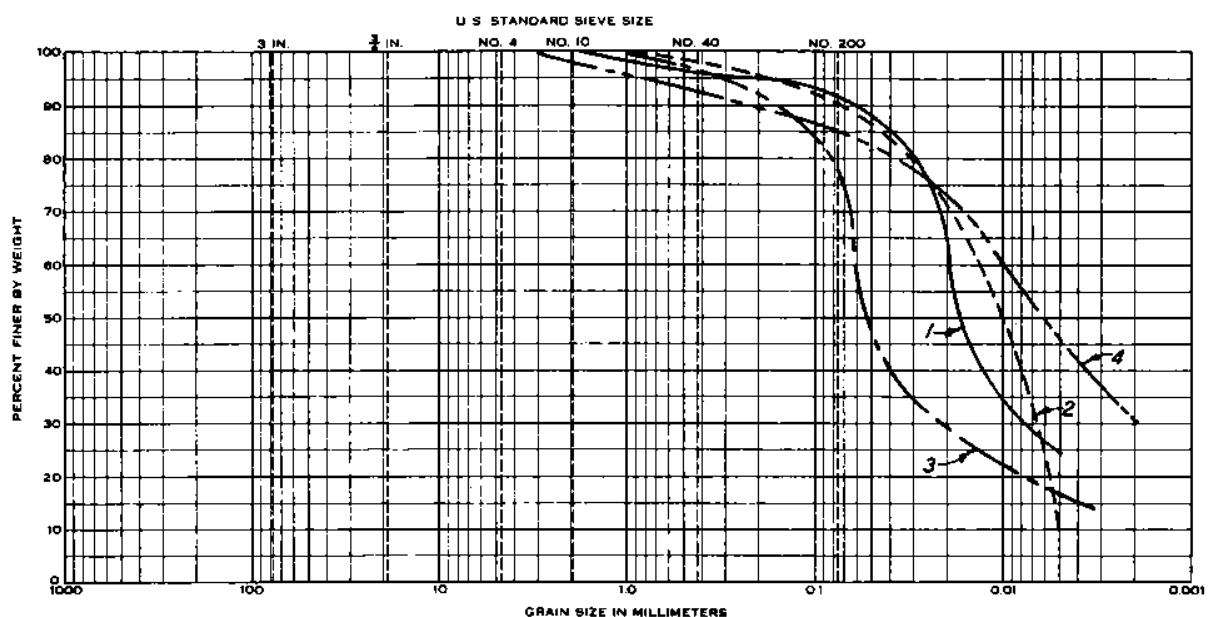

GAAIN SIZE IN MLLLIMETERS

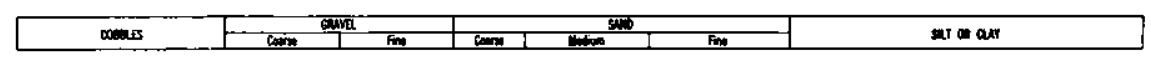

CURVE 1: Lean clay; LL-30, PI-13.
CURVE 2: S11ty clay; LI-25, PI-6. Borderiine, class1fy as CL-MJ.

CURVE 4: Clay; LL-44, PI-25.

CL GROUP

FIG.I

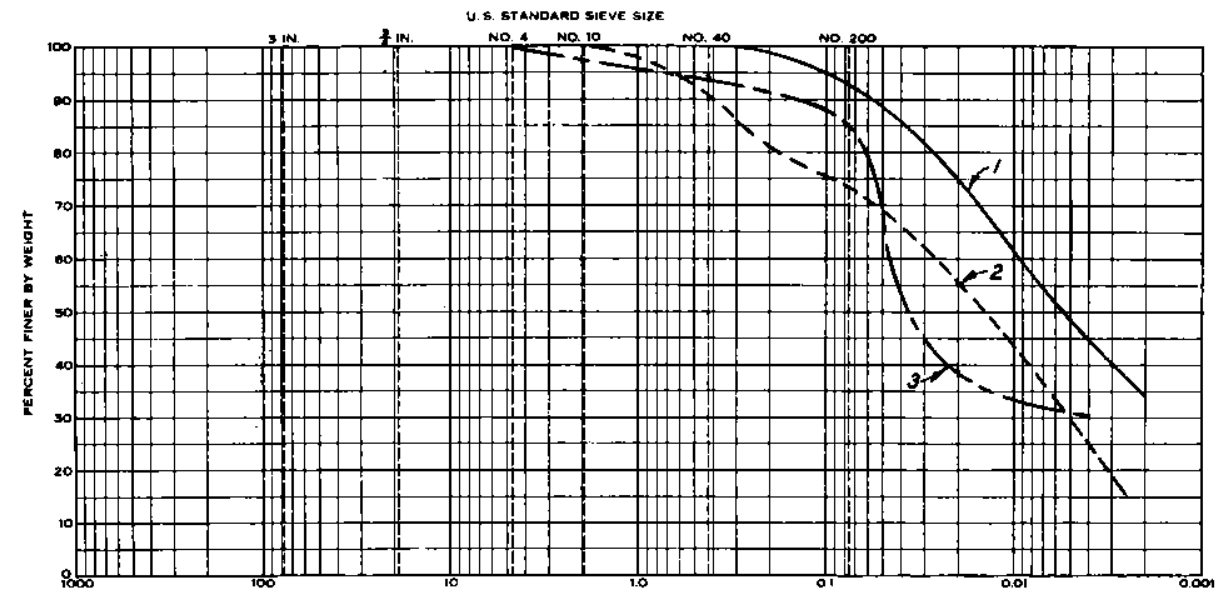

GMAIN SIZE IN MILLIMETERS

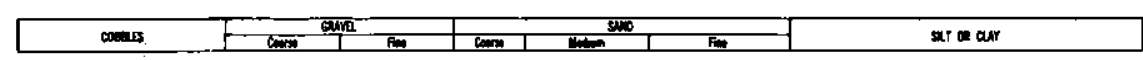

CIRve 1: Silty clay, LT 52 Pr-25.

CURVE 2: Sandy Pat clay; LL-75, PI-45.

CIRVE 3: Sendy clay; Lit?

\section{CH GROUP}

FiG.2

TYPICAL EXAMPLES

CL AND CH SOILS 


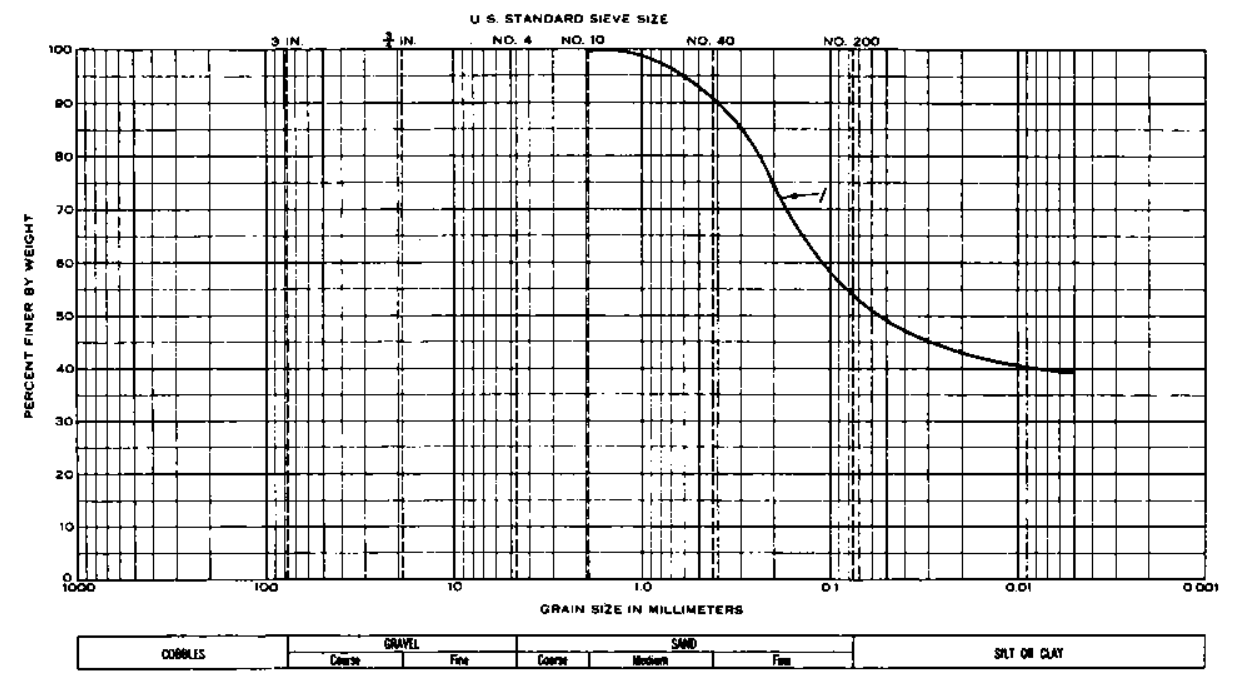

CURVE 1: Organic sandy clay; LL-46, PI-15.

OL GROUP

FIG. I

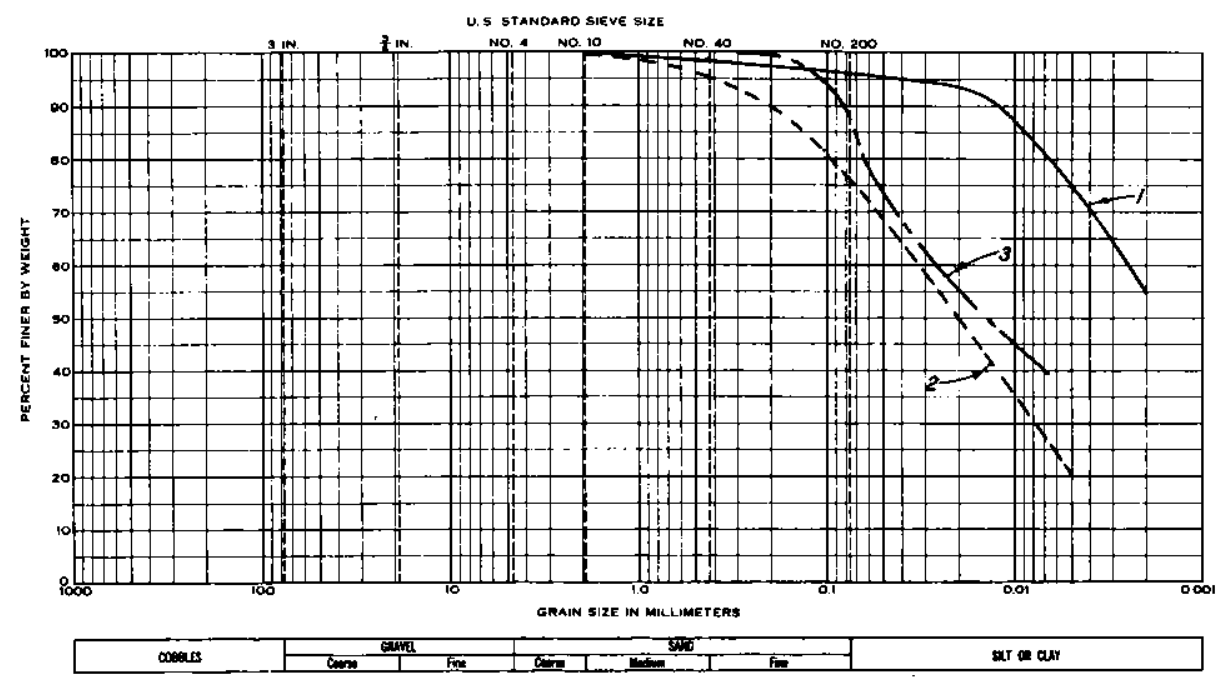

CURVE 1: Organic clay (tidal Plats); LL-95, PT-39.

CURVE 3: Organic s11t; LL-70, PI-33 (natural water content); LL-53, PI-19 (oven dried).

OH GROUP

FIG. 2

TYPICAL EXAMPLES

OL AND OH SOILS

$062852-6$ 

